\title{
RELATIVE INCOME CONCERNS \\ AND THE RISE IN MARRIED \\ WOMEN'S EMPLOYMENT
}

\author{
David Neumark \\ Andrew Postlewaite \\ Working Paper No. 5044
NATIONAL BUREAU OF ECONOMIC RESEARCH
1050 Massachusetts Avenue
Cambridge, MA 02138
February 1995

Postlewaite's research was partially supported by the National Science Foundation. We would like to thank Andrew Foster, George Mailath, Steve Matusz, Mark Rosenszweig, Robert Topel, Ken Wolpin, an anonymous referee, and seminar participants at Michigan State University, the University of Michigan, and the University of Pennsylvania for helpful comments and suggestions, and Sadiq Currimbhoy for research assistance. An earlier version of this paper circulated as CARESS Working Paper No. 93-17. This paper is part of NBER's research program in Labor Studies. Any opinions expressed are those of the authors and not those of the National Bureau of Economic Research.

(C) 1995 by David Neumark and Andrew Postlewaite. All rights reserved. Short sections of text, not to exceed two paragraphs, may be quoted without explicit permission provided that full credit, including $\odot$ notice, is given to the source. 


\title{
RELATIVE INCOME CONCERNS \\ AND THE RISE IN MARRIED \\ WOMEN'S EMPLOYMENT
}

\begin{abstract}
We ask whether women's decisions to be in the labor force may be affected by the decisions of other women in ways not captured by standard models. We develop a model that augments the simple neoclassical framework by introducing relative income concerns into women's (or families') utility functions. In this model, the entry of some women into paid employment can spur the entry of other women, independently of wage and income effects. This mechanism may help to explain why, over some periods, women's employment appeared to rise faster than could be accounted for by the simple neoclassical model.

We test the model by asking whether women's decisions to seek paid employment depend on the employment decisions of other women with whom relative income comparisons might be important. In particular, we look at the effects of sisters' employment on women's own employment. We find strong evidence that women's employment decisions are positively related to their sisters' employment decisions. We also take account of the possibility that this positive relationship arises from heterogeneity across families in unobserved variables affecting the employment decision. We conduct numerous empirical analyses to reduce or eliminate this heterogeneity bias. We also look at the relationship between husbands' relative income and wives' employment decisions. In our view, the evidence is largely supportive of the relative income hypothesis.
\end{abstract}

David Neumark

Department of Economics

Michigan State University

East Lansing, MI 48824

and NBER
Andrew Postlewaite

Department of Economics

University of Pennsylvania

Philadelphia, PA 19104 


\section{Introduction}

What are the important factors in the decision to work? The standard neoclassical model provides an explanation as to why such factors as the wage rate, education, age and past work experience, spouse's income, as well as other personal and household characteristics can affect the decision. This model has been extremely useful in understanding labor supply decisions, but--not surprisingly--there are some cases in which it falls short of providing compelling explanations. We are particularly interested in the rise in the employment of married women in the twentieth century. Empirical estimates of the simple neoclassical model of married women's labor force participation suggest that positive substitution effects outweigh negative own and husbands' income effects, with the consequence that rising real wages draw women into the labor market (Mincer, 1962; Smith and Ward, 1985). But there is ample evidence that this simple model fails to fully explain the rise in the employment of married women.

The theme of this paper is that there may be important variables in women's decisions to enter the work force that are omitted from standard neoclassical models. We specifically focus on the possibility that a woman deciding whether to be in the labor force may be affected by the decisions of other women in ways not captured by standard models. Other women's decisions may affect a particular woman's decision in many ways. For example, other women's decisions will affect the "quality" of remaining out of the work force if there are positive externalities among women who remain at home. Perhaps most importantly (although this remains an open question), to the extent that people may care about their relative income position, other women's decisions to work can change the employment decision.

In this paper we develop a model that augments the simple neoclassical framework by introducing relative income concerns into women's (or families') utility functions. In this model, the entry of some women into paid employment can spur the entry of other women, 
independently of wage and income effects. This mechanism may help to explain why, over some periods, women's employment appeared to rise faster than could be accounted for by the simple neoclassical model.

We test the model by asking whether women's decisions to seek paid employment depend on the employment decisions of other women with whom relative income comparisons might be important, independently of standard variables affecting the employment decision. In particular, we look at the effect on women's employment of their sisters' employment. We also take account of the possibility that a positive relationship may arise from heterogeneity across families in unobserved variables affecting the employment decision. We conduct numerous empirical analyses to reduce or eliminate this heterogeneity bias, including first difference estimation, and looking at sisters matched to sisters-in-law. Finally, we examine the hypothesis more directly by estimating the relationship between husbands' relative income and wives' employment decisions.

Section II of the paper summarizes the salient features of the rise in women's employment in the twentieth century, and empirical research attempting to explain this rise. Section III lays out a version of the theoretical model incorporating relative income concerns. Section IV contains the empirical analysis. Finally, Section V concludes the paper.

\section{The Rise in Married Women's Employment: Evidence and Explanations}

The twentieth century was characterized by rapid increases in women's employment, especially that of married women. ${ }^{1}$ There was a slow acceleration of women's employment prior to 1940 , concentrated among younger women. From 1940 to 1960 employment exploded for women aged 35 and over, with participation rates doubling for women aged 45-54 (to about 47 percent) and women aged 55-64 (to about 35 percent), and increasing by about 50 percent for women aged 35-54 (Smith and Ward, 1985, Table 1). After 1960 the employment of younger 
women accelerated, while the employment of older women held steady or declined, with the participation rate of women aged $25-34$ rising two percentage points a year in the 1970 s. $^{2}$

Mincer (1962) developed the basic neoclassical mocel of married women's labor supply to attempt to explain the increased employment of married women. In this model, women's employment is influenced by two potentially offsetting factors. Rising real wages act through the husband's income to exert a negative income effect on employment. But rising real wages also act through the wife's market wage, with opposing income and substitution effects. Mincer estimated a cross-section model of women's employment, using 1950 Census data on SMSA averages to focus on permanent components of earnings. He found that the compensated substitution effect via the wife's wage dominated the income effect, and the positive uncompensated substitution effect dominated the negative income effect through the husband's wage. Consequently, rising real wages over time would redict rising employment of married women.

In what subsequently became a common empirica: exercise in research on the rise in women's employment, Mincer then used the cross-sectional estimates, along with time-series data on full-time earnings of men and women, to ask whether the cross-section estimates could explain the time-series changes in women's employment. He found that the estimates overpredicted the increase in married women's employment from 1919 to 1929 , accurately predicted the increase for 1929-1939, and underpredicted the increase for 1939-1959 (1962, Table 10). For 1939-1949, his cross-sectional model explained 77 percent of the increase, and for 1949-1959 it explained 68 percent of the increase. ${ }^{3}$

Bowen and Finegan (1969, Chapter 7) carried out a more detailed analysis of the type performed by Mincer, focusing on the post-war period. and exploring the ability of cross-city regressions estimated from different decennial censuses to predict changes in married women's 
employment. Generally speaking, they find that the simple neoclassical model explains considerably less of the time-series increase in women's employment than Mincer found. Their 1960 cross-city regression explains only 25 percent of the increase over the $1948-1965$ period. They attribute the difference to two factors. First, with respect to the $1949-1959$ period, they claim that Mincer understated the rise in husbands' earnings, and hence overpredicted the rise in women's employment. They estimate that this explains about three-fourths of the difference between their predicted changes in employment and those of Mincer. Second, they document the more general point that the simple neoclassical model does particularly well at explaining change in women's employment over the 1940s, but considerably less well in the post-war period.

A similar computation by Smith and Ward (1985) for the period 1950-1980, using income and wage elasticities estimated from a more sophisticated dynamic labor supply model, underpredicted the increase in women's employment over this period, predicting only 58 percent of this increase. Smith and Ward also point out that the neoclassical model runs into particular trouble in the 1970s (and, they could add, the 1980s), when real wage growth ended yet women's employment increased. ${ }^{4}$ They suggest, however, that expected real wage growth may have exceeded actual growth by a substantial amount.

Of course no one would expect such models to explain all of the increase in married women's employment. Researchers have also identified rising education levels and the growth of the clerical sector as potentially partly exogenous factors spurring this increase. Fertility declines over the twentieth century (the baby boom excepted) may also have contributed, although fertility is probably best treated as jointly determined with employment. ${ }^{5}$ Researchers have also pointed to the effects of World War II in bringing women into the workforce, although Goldin (1991) presents evidence that the war had little permanent effect on women's 
employment, based on sample evidence that only about 20 percent of women working in 1950 had entered the labor force during the war, and about half of the wartime entrants left the labor force after the war (p. 755). ${ }^{6}$

An alternative hypothesis regarding the unexplained part of the rise in women's employment stays within the confines of the simple neoclassical model of married women's labor supply, but focuses on potential changes in income and substitution effects that would have led to rising women's employment not predicted by a stable set of cross-sectional estimates. Mincer (1962) argued that the negative income effect on labor supply is likely to have diminished over time. The argument hinges on the assumption that substitutability between home-produced and market-bought goods has increased over time. With low substitutability, an increase in income goes into increased consumption of goods produced in the home (as well as leisure). With increased substitutability, the increase in income is more likely to go partly into increased consumption of goods purchased in the market, hence leading to less of a reduction in market hours of work. Similarly, the declining income effect would increase the uncompensated effect of the wage on women's employment. Both of these changes imply that Mincer's (1962) timeseries experiment with stable cross-section estimates would overpredict the growth of employment early in his sample period, and underpredict it later, given rising income of both husbands and wives.

Goldin (1990) examines this hypothesis by assembling cross-section estimates at various points of time, also based on cross-city variation. Consistent with Mincer's conjecture, she finds that income elasticities appear to have declined consistently throughout the century. But uncompensated wage effects appear to have increased through 1950, and then fallen again, in contrast to Mincer's conjecture. ${ }^{7}$ 
Goldin instead attributes much of the rise in employment to cohort effects, i.e., variables that are fixed for cohorts, rather than contemporaneous effects such as wages or income of husbands and wives. She presents results in which cohort effects (in particular, births and schooling attainment) explain a large fraction (about 35 percent) of the rise in employment from 1890 to 1980 . However, the nature of this empirical exercise does not allow for a comparison of explained and unexplained cohort-specific effects, by including either fixed cohort effects or fixed year effects, because the variables included are fixed by either cohort or year, and hence would be perfectly collinear with such effects. In addition, births are included as a cohort effect, and for white women, at least, appear to be the strongest determinant of employment. But births may be endogenously determined with employment, and hence lead to spurious predictive power.

To summarize, our reading of this literature suggests that the simple neoclassical model goes a long way in explaining the rise in married women's employment. However, it is safe to say that, not surprisingly, the model cannot fully explain the rise. In the next section, we develop a formal model that can explain the "faster than expected" growth in married women's employment, via peer- or reference-group effects driven by relative income comparisons. The incorporation of concerns over relative income has become popular in other models, especially in labor economics (Duesenberry, 1949; Akerlof, 1982; Summers, 1988; Frank, 1985), to attempt to explain otherwise anomalous behavior. We are interested in exploring whether such concerns may also help to explain the rise in married women's employment.

\section{A Relative Income Model of Women's Employment}

\section{III.1 The neoclassical world}

There is a continuum of couples, each consisting of a man and a woman. Each woman is characterized by an ability level denoted by $\mathbf{a}$, and each man is characterized by an ability level 
denoted by $\mathbf{b}$. We assume that $\mathbf{a} \in(\mathbf{0}, \mathbf{A}]$ and $\mathbf{b} \in(0, \mathbf{B}], \mathbf{A}, \mathbf{B}<\infty$. A person who works earns w $(>0)$ per unit of ability. We assume all men work. We want to capture the idea that there is an opportunity cost to a woman working, which we interpret for now to represent lost household production. ${ }^{8}$ In theory this opportunity cost might depend on a number of variables including family income, the woman's ability, the number and ages of the children the couple might have, and so on. For our purposes, we will assume that the opportunity cost depends only on the husband's income, that is, there is a function $\mathbf{v}(\mathbf{i})$ that specifies the value of the woman's home production. If the wage rate is $\mathbf{w}, \mathbf{a}$ couple whose abilities are represented by $(\mathbf{b}, \mathbf{a})$ will have utility $(\mathbf{a}+\mathbf{b}) \mathbf{w}$ if the woman works and $\mathbf{b} \mathbf{w}+\mathbf{v}(\mathbf{b} \mathbf{w})$ if she does not. We assume $\mathbf{v}>\mathbf{0}$, that is, that higher income families put higher value on the home production of the woman. A consequence of this form for the opportunity cost is that of the women matched with men of the same ability level $\mathbf{b}$, it is those women with the highest ability who will work, since women work if $\mathbf{a}>\mathbf{v}\left(\mathbf{b}_{\mathbf{b}} \mathbf{w}\right) / \mathbf{w}$. Figure 1 illustrates the set of possible characteristics of couples, with the set divided into two components: those couples with $(\mathbf{b}, \mathbf{a})$ such that $\mathbf{a}>\mathbf{v}(\mathbf{b} \mathbf{w}) / \mathbf{w}$, in which utility is higher if the woman works, and those for whom the reverse holds.

We are interested in the effect of an increase in the wage rate, $w$, on women's employment. ${ }^{9}$ If we fix the ability of the man at level $\mathbf{b}$, a woman with ability a who is matched to this man, where $\mathbf{a}$ is such that $\mathbf{a} \mathbf{w}=\mathbf{v}(\mathbf{b} \mathbf{w})$, is indifferent between employment and nonemployment, while any woman with higher ability married to a man of this ability will strictly prefer employment. In other words, the marginal woman matched with a man of ability $\mathbf{b}$ has ability $a=v\left(b^{w} w\right) / w$. If we differentiate this with respect to $w$, we find $\partial a / \partial w=\left(v^{\prime} b-a\right) / w$. $\partial a / \partial w$ will be negative if $\mathbf{v}^{\prime}(\mathbf{b} w) b<a$; that is, if $\mathbf{v}$ does not increase too quickly, increases in 
the wage rate will result in increased women's employment. We assume that this holds for all values of $\mathbf{a}, \mathbf{b}$, and $\mathbf{w}$.

We can see from Figure 1 what the effect of an increase in the wage would be on women's employment. As mentioned above, the woman in a couple with abilities $(\mathbf{b}, \mathbf{a})$ will work if $\mathbf{a} w>\mathbf{v}(\mathbf{b} w)$. Suppose a woman does not work when the wage rate is $\mathbf{w}$ but enters the workforce when the wage increases to $\mathbf{w}^{*}$. It must be the case then that $\mathbf{a} w<\mathbf{v}(\mathbf{b} \mathbf{w})$ and $a w^{*}>\mathbf{v}\left(\mathbf{b} \mathbf{w}^{*}\right)$. If we let $\mathbf{a}^{\prime}=\left(\mathbf{w}^{*} / \mathbf{w}\right) \mathbf{a}$ and $\mathbf{b}^{\prime}=\left(\mathbf{w}^{*} / \mathbf{w}\right) \cdot \mathbf{b}$, then $\mathbf{a} \cdot \mathbf{w}^{*}>\mathbf{v}\left(\mathbf{b} \mathbf{w}^{*}\right)$ if and only if $\mathbf{a}^{\prime} \cdot \mathbf{w}>\mathbf{v}\left(\mathbf{b}^{\prime} \mathbf{w}\right)$. That is, the increase in the wage rate from $\mathbf{w}$ to $\mathbf{w}^{*}$ will cause the woman to enter the labor force if and only if a proportional increase in their abilities that resulted in the same wages would cause the woman to enter the labor force. Another way to say this is that if one wished to predict whether the woman in the couple with abilities $(b, a)$ would work when the wage increased by a specified amount, one could check whether a woman in a couple with higher abilities in proportion to the wage increase works at wage $\mathbf{w}$. This latter calculation is effectively the cross-section estimate of the wage effect on employment. Thus, the assumption made at the end of the previous paragraph assures that our model replicates Mincer's (1962) finding that the positive uncompensated substitution effect of general wage increases on women's participation dominates the negative income effect through the husband's wage.

\section{III.2 The effect of ranking concerns}

The phenomenon that we are interested in is a particular externality between couples. The externality is one in which when the woman in one couple enters the labor force, this decreases the reservation wage for the woman in the comparison couple. There are a number of reasons that might underlie such a concern. For example, if in all the couples with whom one socializes, the wives begin to work, then dinner outings, cocktail parties, etc., may become more elaborate and more expensive. To the extent that we believe that a couple's utility may 
depend on the probability of retaining their friends, a woman's reservation wage will naturally be affected by other women's decisions to work. One can think of this story as explaining how the indirect utility for money in a reduced form mode: might depend on the labor supply decisions of acquaintances. Alternatively, there are natural ways in which the opportunity cost associated with a woman's working might depend on other women's labor supply decisions. The reservation wage for a given woman is the utility a uoman gets when at home rather than in the labor force. This may well be affected by whether a close friend is at home or working. Besides the pure recreational value of that person's cumpany, it may be possible to share child care responsibilities or other work only when both a ce out of the labor force.

While there are many ways in which the optimal participation decision for a woman may depend on the decisions of other women, we will simply assume that couples are concerned with their relative income position. There is a broad anr y of specific forms such a concern might take, such as a concern with how far one is from the top of the income distribution, how far from the bottom, or one's percentile rank in the discribution. While we believe that it is perfectly plausible that there is a concern with relative position, we are not confident about the precise form. It is quite reasonable to believe that the specific form varies from couple to couple and often is some composite of a number of different aspects like those mentioned above. For our purposes, we will assume a particularly sinple form of the concern that has two advantages. First, it provides clear and unambiguous predictions about the effect of ranking concerns on women's employment decisions, and second, it parallels our empirical work. However, the qualitative characteristics of the equilibrium with which we are most interested are not driven by the particular form of the relative income concern; how the results of our model might change as we vary the form of the ranking concern is discussed in Section III.4. 
We assume that each couple is concerned with its relative position vis-a-vis a particular comparison couple. That is, the set of all couples is broken into pairs with members of each pair of couples comparing themselves with the other couple in the pair. We assume that the benefit of being the higher income family generates an increase in utility equal to $c>0$. The increase $c$ is independent of the size of the difference in incomes. We will further assume for now that $c$ is greater than the opportunity cost of the home production value of a woman's time, i.e., $\mathbf{c}>\mathbf{v}(\mathbf{b} \mathbf{w})$ for all $\mathbf{b}<\mathbf{B}$. We assume that couples are matched randomly so that for any given couple, the distribution over the characteristics of couples with whom they compare themselves is the same as the unconditional distribution over couples' characteristics. As with the form of the concern, our assumptions about the size and determinants of the benefit and the couples with whom a given couple will compare themselves are made primarily for reasons of tractability. We will discuss below how the choice of alternative forms would affect the nature of our results.

To see how the concern with relative position affects women's employment decisions, we first note that for those couples $(\mathbf{b}, \mathbf{a})$ with $\mathbf{a} w>\mathbf{w}(\mathbf{b} \mathbf{w})$, women will work. That is, if women were better off working than not when ignoring ranking concerns, the inclusion of the ranking consideration will not cause them to leave the labor force. Any effects of the ranking consideration will show up in the decisions of those women who in the absence of ranking concerns would decide not to work.

To see how the inclusion of ranking considerations might affect a woman's decision to enter the labor force, consider a couple $(b, a)$ in which the woman would not be working in the absence of ranking considerations, depicted in Figure 2. The set of couples who have the same combined ability as the given couple is shown by the straight line (with slope -1 ) through the point $(b, a)$. If both the man and the woman in the couple whose characteristics are on this line 
work, they will have higher combined income than any couple whose characteristics are below the line. In addition, they will have higher income than any family with characteristics (b', $\left.\mathbf{a}^{\prime}\right)$ with b' $<$ b such that the woman does not work. If the woman in the couple with characteristics (b,a) does not work, the couple will have higher income than those families with characteristics below the line with horizontal intercept $\mathbf{b}$ and slope -1 , plus those couples in which the man's ability is less than $\mathbf{b}$ and the woman does not work.

We are most interested in those comparison couples whose incomes would be higher than $(\mathbf{b}, \mathbf{a})$ 's income if the woman in (b,a) works, but lower if she does not work, even if the woman in the comparison couple works. This is precisely the set of couples who will be "jumped over" if the woman in (b,a) decides to work. The shaded regions in Figure 2 represent these comparison couples. In the lower (right-hand) shaded region (R), the woman in the comparison couple is not working, but the comparison couple would have lower income even if she did work. Although the ability of the husband in the comparison couple, b', is greater than the ability of the husband in the given couple, this is more than offset by the lower ability of the woman in the comparison couple (a'). For any couple in the upper left-hand shaded region (S), the woman in the comparison couple is already working, and if the wife in couple $(\mathbf{b}, \mathbf{a})$ works, this couple earns higher income than the comparison couple. Thus, for the sets of couples in these shaded regions, we need not be concerned with possible reactions of the comparison couple in determining the incentives facing the woman in our given couple $(\mathbf{b}, \mathbf{a})$.

The issue of the comparison couple's reaction does arise, however, with respect to comparison couples that could revert to earning higher income if the wife responds by also going to work. Consider a couple (b', $\left.\mathbf{a}^{\prime}\right)$ with $\mathbf{a}^{\prime}+\mathbf{b}^{\prime}>\mathbf{a}+\mathbf{b}^{\prime}>\mathbf{b}^{\prime}$ and $\mathbf{b}^{\prime}<\mathbf{v}\left(\mathbf{b}^{\prime}\right.$ w). In Figure 2 , such a couple would be represented by a point in the region $(T)$ formed by the vertical line 
through $\mathbf{a}+\mathbf{b}$ on the horizontal axis, the diagonal through $(\mathbf{b}, \mathbf{a})$, and the curve $\mathbf{v}(\mathbf{b} \mathbf{w}) / \mathbf{w}$. The second inequality implies that in the absence of ranking concerns, the woman in this couple (as the woman in our given couple) would not work. A consequence of the first inequality, however, is that starting from a position in which neither woman is working, the couple $(\mathbf{b}, \mathbf{a})$ can jump over the couple (b', $\left.\mathbf{a}^{\prime}\right)$ if the wife goes to work, but if the woman in $\left(b^{\prime}, a^{\prime}\right)$ also enters the labor force, the ranking reverts to the original order.

Our exclusion of couples in region $T$ from the set which would represent a reversal of the two couples' ranks warrants a brief discussion. We have not specified precisely the game form representing the strategic interaction of the couples, and will avoid doing so. It is straightforward to construct numerous such game forms for which the outcome we are focusing on--that in situations such as those above, neither woman enters the labor force--is an equilibrium. More importantly, however, for many such game forms the only equilibrium outcomes will be the ones on which we are focusing. Suppose the game is a sequential game in which there is no "last mover," that is, whenever the woman in one couple enters the labor force the woman in the comparison couple can respond to that decision by entering herself. For such a game, a best response for a couple whose characteristics satisfy the inequality in the above paragraph would be for the woman to enter the labor force if the woman in the couple $(b, a)$ entered. Thus, in any Nash equilibrium, the woman in couple $(b, a)$ entering the labor force would always be followed by the woman in the comparison couple entering as well. Thus, for equilibria of such game forms, it is appropriate to exclude those couples in region $\mathrm{T}$.

Essentially the same issue arises with respect to a couple with characteristics satisfying $a+b>a^{\prime}+b^{\prime}>b^{\prime}$ and $b^{\prime}<\mathbf{v}\left(b^{\prime} w\right)$. Couples $\left(b^{\prime}, a^{\prime}\right)$ satisfying this inequality are those in the unshaded trapezoidal region $(U)$ in Figure 2. For a couple represented by a point in this 
region, because of ranking concerns the woman in $\left(b^{\prime}, a^{\prime}\right)$ would work if the woman in $(b, a)$ did not, but the couple (b,a) could jump back ahead if the woman in this couple worked.

What then is the female labor supply with this ranking effect added? First, as mentioned above, all women in couples with characteristics above $v(b \mathbf{w}) / \mathbf{w}$ will work. In addition, some women in couples below that line will work, namely those for whom the comparison couple lies in the shaded regions for that couple. Thus, we see that for any characteristics below the line $\mathbf{v}(\mathbf{b} \mathbf{w}) / \mathbf{w}$, the proportion of the women in a couple with those characteristics who are in the labor force is equal to the proportion of women in the shaded regions. It is straightforward to see that the probability that a woman married to a man with ability b works is an increasing function of her ability.

\section{III.3 "Cross-section" predictions of "time-series" increases in employment}

To see that this model may explain why married women's employment rose faster than predicted by the simple neoclassical model, consider what predictions we might make about the effects of wage changes on employment if we fail to take account of ranking considerations. If we look at a couple (b,a) as making a decision independent of those made by other couples, an increase in the wage rate will have two effects: the extra income the woman can earn goes up because of her own ability, and the opportunity cost goes up because of her husband's increased income. We can think about generating a cross-section estimate of the effect of the wage on the proportion of women working from differences in the proportion of women working between couples with different levels of ability. For example, since the choice the couple $(b, a)$ makes depends on the potential income of the woman and the actual income of the man, we can find existing couples whose potential and actual incomes today are precisely the same as those the couple $(b, a)$ would be faced with given any hypothetical wage increase. Our prediction would 
then be that the proportion of the women in couples $(b, a)$ who will be in the labor force when the wage rate goes up by this amount is equal to the proportion of those higher ability couples for which women are working today. For the interesting case of women who would not work in the absence of ranking concerns, this proportion is represented by the two shaded regions in Figure 3. ${ }^{10}$ These are comparable to the shaded regions $R$ and $S$ in Figure 2, but shifted to the right.

For our model, this would be an accurate estimate of the probability that the woman in the couple $(b, a)$ would work if the wage increased for this couple only. If this is a general wage increase that affects all workers, however, this analysis will miss an important effect. We are assuming that the nature of the function $v$ is such that when the wage rate goes up, women's employment goes up for purely economic reasons (that is, excluding ranking considerations). But this increases the set of couples for whom the ranking will be reversed if the woman in this couple enters the labor force. In Figure 4, the increase in the set of comparison couples which would induce the woman in $(b, a)$ to enter the labor force is shown by the lightly shaded region. Thus, the wage increase causes a "purely economic" increase in women's employment, which in turn amplifies the incentives for women to enter for ranking considerations. ${ }^{11}$ To sum up, our estimate from cross-section covariation between employment and wages of the proportion of women who will enter the labor force in response to a wage increase ignores the increased incentive for women to enter the labor force, which imparts a downward bias (toward zero) to the estimated wage effect. Thus, the model with ranking concerns may help to explain why cross-section estimates of women's employment equations fail to fully predict the time-series increase in women's employment. 


\section{III.4 Discussion of model}

Naturally our model incorporates a number of simplifying assumptions. While we take these assumptions to be plausible, we want to point out that they have been made for reasons of tractability and do not drive the main qualitative result in which we are interested, namely that the use of cross-section data to estimate the elasticity of female labor supply with respect to wages may result in estimates that are biased toward zero if ranking considerations are not taken into account. We now discuss briefly the nature of the various assumptions and how changes would affect our main conclusions.

We assumed that the opportunity cost of a woman's working was a function of the man's income only. The effect of this assumption is to generate increased women's employment when the general wage rate goes up. It was this increase that caused there to be a secondary effect due to the entrance of women into employment because the woman in the comparison couple entered the labor force. We would expect a similar effect even if the opportunity cost was a more complicated function that depended also on the number and ages of children, the woman's ability, etc. As long as wage increases lead to increased female employment excluding ranking considerations, including ranking considerations will amplify the employment increase. It would be more difficult, however, to make a simple argument that cross-section estimates of the effects of wages on employment are biased downward, because it would be significantly more difficult to trace through the model the effects of wage increases.

We also assumed that the wage rate per ability unit is the same for men and for women. If women earned some fixed percentage of men, this could be incorporated into the abilities; that is, one could simply multiply women's abilities by this fixed percentage. What this assumption does not allow for is varying rates of wage increases for men and women. One could easily write down an extension of our model to allow for such differences, and one would expect the 
same qualitative conclusion that estimates of wage elasticities would be biased downward. This is for essentially the same reason as mentioned just above: the bias comes from the amplification of the employment effect due to ranking considerations.

We assumed that the couples were paired randomly with respect to the ranking comparison. This is likely the least plausible of our simplifying assumptions. We might believe that there is substantial homogeneity in the characteristics of couples in comparison groups. At first pass, we can say the same thing as in the previous two comments: this will not alter the fact that wage increases lead to increased female employment for purely economic reasons, and hence the ranking considerations will amplify the effect. Here, however, we will speculate a bit about the magnitude of the effects. We are only interested in the model if the size of the bias is not trivial. It could be that the amplification that we have identified is more or less insignificant. This would be the case if the probability that a given couple could jump over its comparison couple changed little when the wage rate increased. But if couples compare themselves to other couples with similar characteristics, this probability should be higher than in the case we considered. Thus, although one has to be careful about how one made the comparison relation more realistic, one would expect the effect we are focusing on to become more important.

We also assumed that the benefit of "beating" the comparison couple generated a fixed utility increment $c$ that was greater than the opportunity cost of any woman's working. It is clear that allowing the benefit to differ across couples will have only a quantitative effect, not a qualitative one. Furthermore, given the discussion above, we might expect the comparison couples to be similar. But this implies that when a woman enters employment for purely economic reasons, the woman in the comparison couple may prefer not to work, but the decision will be close. Hence, a small increment $\mathrm{c}$ may send her to work. 
Allowing the increment $\mathrm{c}$ to depend in a more sophisticated way on the ranking might raise one difficulty. If the increment depended on the amount by which a couple's income exceeded the comparison couple's, then in light of the previous suggestion that comparison couples have similar characteristics, a woman who would otherwise not have wanted to work will gain little by working since the amount by which incomes will differ if both women work will be small. On the other hand, if we allowed c also to be negative if you "lost" the income race, the situation would be more or less as in our analysis.

Probably more significant than the detailed assumptions we made within our model are several that are embedded within the basic structure of the model. First, we have assumed that couples care whether they have higher income than their comparison couple. While we are convinced of the plausibility of such concerns, it is of interest to understand the basis of them. At the simplest level, it can be posited that these are the preferences of people, but this is generally not very satisfactory. It is well understood that if one is "allowed" to put any variable in the utility function, one can "explain" everything. We discussed at the beginning of this section how our concern for ranking might arise as a reduced form of models in which there was no direct concern for ranking, but rather that relative ranking affects some nonmarket decisions (e.g., the social opportunities mentioned above). ${ }^{12}$

A second defense of our approach is that it generates testable restrictions. The model does not automatically lead to the conclusion that cross-sectional estimates of the elasticity of female labor supply will be biased down. For small enough gains from being the higher income couple or for large enough opportunity costs of entering the labor force, there will be no relative income effects on women's employment. Further, the model can be extended in simple ways so as to generate secondary and tertiary implications of the central ideas that can themselves be tested. For example, if we were to allow other shocks to a family's income such as shocks to 
the man's income or bequests from the man's family, such shocks should have an effect on the labor supply decisions of the woman in the comparison couple. The central idea of the model-that relative income matters--is specified in sufficient detail at the micro level that we need not be concerned that we cannot reject the hypothesis.

We argued above that the important aspect of our model is that there be an externality associated with a woman's decision to work. One of the examples illustrating how an externality might arise centered on the decrease in utility a nonworking woman might suffer when a close friend entered the labor force. The utility decrease might lower the reservation wage for such a woman. One can slightly alter our model to allow a utility increment c only if both the woman herself and the woman in the comparison couple are not working. The analysis and conclusions are essentially unchanged, with one exception. The sort of pure externality described above might lead to a utility loss to a woman who enters the labor force when the woman in the comparison couple is out of the labor force. This could lead to a situation with multiple equilibria; it could be optimal for each woman in a pair of matched couples to be out of the labor force if the other woman is, yet be optimal to be in the labor force if the other woman is. ${ }^{13}$ A model that is similar to ours but based on such externalities rather than income comparisons could then have an "inertial" property that entry initially is slower than would occur in the absence of the externality. We say "could" because there would be delay in one of the multiple equilibria. Despite the possibility of the initial delay, once entry starts to occur, it would occur more rapidly than would be expected in the absence of the externality for much the same reason as in our model: one woman's entry into the labor force lowers the reservation wage for the woman in the comparison couple. ${ }^{14}$

Another feature of the model that should be discussed is the built-in assumption that the externality, or the comparison group for relative income concerns, is confined to two couples. 
There are several things to be said about extending our model to larger comparison groups. First, the basic logic of our model should carry over with little change. As more women become employed for purely economic reasons, this provides an additional incentive for other women not employed to become so. Second, extending the model does not present many technical difficulties. In discussing the effect of wage increases when ranking matters, we mentioned one difficulty that arose, namely that for a woman contemplating entering the labor force to know what the net benefit would be, she needed to predict the reaction of the woman in the comparison group. We made the simplifying assumption that the second woman would enter if doing so restored her to first place. This assumption simplified the analysis of the first woman's decision whether to work. Any extension to larger groups would exacerbate the problem of forecasting the decisions of other women in a comparison group.

\section{Empirical Analysis}

\section{IV.1 The empirical approach}

The model developed in the previous section suggests that women's employment decisions may depend not only on the individual-level variables included in standard employment equations, but also on the employment decisions ${ }^{15}$ or relative income of other women with respect to whom relative income comparisons are made. This suggests that we might want to incorporate into a standard employment equation information on the employment status of such other women. In principle, surveys could elicit information on the employment status of women's peers, although we are not aware of any surveys that do so. A potential problem with such data, however, would be that individuals may choose or define their peer groups so that their relative income is high compared to that of their peers. That is, the definition of one's peer group could be contaminated by relative income concerns. Thus, we instead focus primarily on what might be interpreted as "exogenously given" peers, namely a woman's sisters. 
As a general matter, the types of relative income concerns or externalities that we discussed in the previous section suggest that we want to ask whether women's employment decisions depend on the employment decisions of their sisters, independently of standard variables suggested by the neoclassical model of the employment decision. We do not interpret equations relating women's own employment to their sisters' employment as representing structural relationships obtained from the model. Specifying such structural relationships would require strong assumptions regarding functional form, the game facing sisters in their employment decisions, the nature of the rankings, etc., as well as data related to husbands' and wives' abilities or productive capacities. Rather, we view the empirical exercise primarily as testing the plausibility of a model that augments the neoclassical model with relative income concerns or externalities among women with respect to their employment decisions.

To begin, we posit a standard equation for an unobserved propensity to work (IV.1) $E_{i t}^{*}=X_{i t} \beta+\epsilon_{i t}$ $E_{i t}$ is an observed dummy variable equal to one for woman $i$ in period $t$ if $E_{i t}^{*}>0$ and she is therefore employed, and $X_{i t}$ is a set of standard control variables. For the most part, the variables in $\mathrm{X}$ are assumed to be determinants either of the market wage or the value of home production. Thus, the argument made in the previous section regarding cross-section estimates of wage effects on employment carry over to the effects of most of the variables in $\mathrm{X}$. We estimate equation (IV.1) as a logit model.

We then add to the employment equation the observed employment status of the sister, E'

$$
E_{i t}^{*}=X_{i t} \beta+E_{i t-1}^{\prime} \gamma+\epsilon_{i t} \cdot{ }^{16}
$$

In principle, testing whether $\gamma>0$ is a test of an implication the presence of relative income concerns or externalities, in that $\gamma>0$ implies that, independently of a woman's own characteristics thought to affect employment, her sister's employment status also matters. ${ }^{17}$ 
However, a positive estimate of $\gamma$ in equation (IV.2) does not necessarily imply a causal relationship between women's sisters' em loyment and their own employment. Rather, it may reflect any of a number of variables that .jre common across sisters, affect employment, and are unobserved. Sisters may live in similar iabor markets, they may face similar influences on lifetime wealth (through, for example, bcquests, or medical expenses for parents), and they may have similar tastes regarding the leisure-abor tradeoff. Alternative approaches to controlling for this possible heterogeneity bias will receive considerable attention in the following analysis. ${ }^{18}$

After looking at the relationship setween the employment of sisters, we turn to a test that is more directly motivated by the model we developed in the previous section, including the specific assumptions regarding the comparison group, etc. The test is most easily explained by looking at Figure 2. In Figure 2, a wcman's employment decision should be unaffected by her sister's employment unless her sister and her sister's husband fall in regions $\mathbf{R}$ and $\mathbf{S}$. If they fall in region $R$ or $S$, the woman work; even though she would not have worked in the absence of relative income concerns. Thus, in terms of the precise details of this figure, a positive estimated relationship between $E$ and $E^{\prime}$ arises from the fraction of women whose sisters (and their husbands) are in region S. On the other hand, the figure indicates that for women whose sisters are in region $R$, a negative relationship between $E$ and $E$ ' is predicted. Thus, taking the figure literally, the model does not ntcessarily predict a positive relationship between $\mathrm{E}$ and $\mathrm{E}^{\prime} .{ }^{19}$ A positive relationship will only arisc if the fraction of sisters in $S$ tends to exceed the fraction of sisters in R. Nonetheless, a positive relationship (controlling for heterogeneity bias) is consistent with our model, but not the standard neoclassical model.

However, the model as depicted in the figure does make some more precise predictions. First, if a woman's sister is not employed, the woman should be more likely to work if her sister's husband earns more than he- own husband. To see this, note that if her sister is not 
employed, then her sister (and her husband) lie somewhere below the $v(b \mathbf{w}) / \mathbf{w}$ locus. The woman has no incentive to work if her sister's husband's ability is less than b (her own husband's ability), but does have an incentive to work if her sister's husband's ability is greater than b. This makes intuitive sense. If the sister's husband earns less than a woman's own husband, and the sister does not work, then the woman does not need to work in order for her family's income to be higher. However, if the sister's husband earns more than her own husband, and her sister does not work, then by going to work, the woman may be able to "win" the income race. She will be able to do so precisely when her sister lies in the region $\mathrm{R}$. So a positive estimated relationship between the woman's employment and her sister's husband's relative income arises from the fraction of women with comparison couples in region $\mathbf{R}$. By the same token, if her sister is employed, then the woman's employment should be negatively related to her sister's husband's relative income. In this case, the sister (and her husband) lie above the $\mathbf{v}(\mathbf{b} w) / \mathbf{w}$ locus. The only case in which the woman can "win" the income race is if the sister's husband's ability is less than b. In particular, if her sister (and her husband) lie in the region $\mathrm{S}$, she has to work in order to attain higher family income.

Therefore, we also estimate the equation

$$
E^{*}{ }_{\mathrm{it}}=\mathrm{X}_{\mathrm{i} \ell} \beta+\mathbf{R}_{\mathrm{it}} \gamma+\epsilon_{\mathrm{it}},
$$

where RI is a dummy variable equal to one if the sister's husband's income exceeds the woman's own husband's income. ${ }^{20}$ The model predicts that the estimate of $\gamma$ should be positive if the sister is non-employed, and negative if the sister is employed. We do caution, though, that the results of these tests should be interpreted less definitively, since, as we indicated in the previous section, the precise model depicted in Figure 2 is based on numerous assumptions that were made to simplify the analysis, but which may be unrealistic. 


\section{IV.2 The data}

The data are extracted from the National Longitudinal Survey of Youth (NLSY). The survey contains many multiple-respondent households, consisting of individuals in the age range of the initial sample (14-22) in 1979 who were living in the same household. We excluded women in the NLSY's military subsample. We then matched up all sets of sisters, randomly choosing two sisters from sibships with three or more sisters. ${ }^{21}$ For each woman in this sister sample we identified the first observation after which she had left school, which means that she did not re-enroll in subsequent years of the survey (which extends through 1990). For each woman, we extracted information on employment status in each year after leaving school, as well as standard control variables typically used in employment equations (education, number of children, marital status, husband's income, other non-labor income, etc.).

Because of the strong persistence in married women's participation and employment (Goldin, 1991), we view the relative income hypothesis primarily as explaining why some women choose to work, and others do not, rather than as an explanation of year-to-year transitions into and out of employment. Consequently, we use the earliest possible data on women, and do not utilize the full longitudinal structure of the NLSY. In particular, we selected data for the first two contiguous years on each sister in each pair for which both sisters were out of school and both had been married by the time of the first observation. We required two years of data on each woman because some methods of addressing heterogeneity bias will entail using data on an individual woman's lagged employment, and because the influence of one sister's employment on another may occur with a lag. ${ }^{22}$ This led to a sample of 173 sibling pairs. Descriptive statistics are reported in Appendix Table A1. The data set is constructed to contain one record for each woman in the sample. Thus, there are two observations for each sibling pair, one with one sister as the unit of observation whose employment is to be explained 
(perhaps partly by her sister's employment), and another with the other sister as the unit of observation.

\section{IV.3 Basic results on employment of women and their sisters}

Logit estimates of equation (IV.1) are reported in columns (1) and (2) of Table 1 . We report two specifications. The one in column (1) includes only measures of husband's income and other income, both perhaps regarded as exogenous by the wife, ${ }^{23}$ the woman's level of education, which proxies for her wage, ${ }^{24}$ and the local unemployment rate. ${ }^{25}$ The estimated signs of the coefficients are as expected. The specification in column (2) adds demographic controls and a dummy variable for whether the husband was unemployed and collected unemployment compensation during the past calendar year. ${ }^{26}$ Of course controls such as marital status and number and age of children are potentially endogenous variables. The estimated signs of the coefficients of the income variables (negative), education (positive), and the local unemployment rate (negative) are as expected. The estimated coefficient of the husband's unemployment variable is negative and significant at the ten-percent level, suggesting that the discouraged worker effect dominates the added worker effect for this sample. Children, and especially young children, appear to have significant negative effects on women's employment.

As a first step in testing the model, we add to the employment equation the lagged employment status of the sister, as in equation (IV.2). Estimates are reported in columns (3) and (4) of Table 1 . In both columns, the estimate of $\gamma$, the coefficient of sister's employment, is positive and statistically significant. ${ }^{27}$ As reported in square brackets below the standard errors, women with employed sisters are 17 to 20 percent more likely to be employed, when the probability expressions are evaluated at the sample means. The other estimated coefficients are little changed from those in the first two columns of the table. 


\section{IV.4 Heterogeneity bias}

So far, the evidence is consistent with a strong effect of a woman's sister's employment on her own employment decision, which is an implication of the relative income model. But for reasons discussed above, this evidence may reflect heterogeneity bias arising from a common family component in the error term of equation (IV.2). We now turn to a variety of statistical experiments that address the potential importance of this heterogeneity bias.

\section{Including lagged own employment}

First, in columns (5) and (6) of Table 1 we include in the employment equations a dummy variable for each woman's own lagged employment status,

$$
\mathrm{E}_{\mathrm{it}}^{*}=\mathrm{X}_{\mathrm{i} \beta} \beta+\mathrm{E}_{\mathrm{i}-1}^{\prime} \gamma+\mathrm{E}_{\mathrm{it}-1} \theta+\epsilon_{\mathrm{it}} .
$$

While the lagged own-employment variable may reflect state dependence as well as heterogeneity (Heckman, 1981), it should certainly capture heterogeneity.

The estimates reveal considerable evidence of persistence across time in individual women's employment decisions. The estimated coefficients of lagged own employment are positive and statistically significant, and, controlling for everything else, women employed one year ago are about 30 percent more likely to work in the current year (evaluated at the means). However, the positive, significant effect of lagged sister's employment persists in these specifications, although the magnitude of the effect (reported as the partial derivative in square brackets) falls by about 40 percent. Nonetheless, controlling for everything else, including the woman's own lagged employment, women are about 10 percent more likely to work if their sister worked in the previous year. ${ }^{28}$ We note that these results could understate the effect of sisters' employment, since the woman's own lagged employment may partly reflect past employment decisions of her sister. 
Variation in comparison effects with geographical proximity

The relative income model also suggests that women's employment decisions should be more sensitive to their sisters' decisions if they are likely to engage in relative income comparisons. It seems likely that such comparisons are more important and more likely to occur when sisters live in close proximity to one another. Distinguishing effects based on proximity should also be informative about heterogeneity bias, since some potential sources of heterogeneity would not have this implication. For example, if this heterogeneity arises from tastes, or from common influences on wealth, then the association between sisters' employment should not be related to geographic proximity. On the other hand, this exercise is not definitive, since some sources of common unobserved variables, such as unmeasured local labor market conditions, may be stronger for sisters living close to one another ${ }^{29}$ Thus, in columns (1) and (2) of Table 2 we reestimate the models from columns (5) and (6) of Table 1 adding interactions between lagged sister's employment and dummy variables indicating whether or not sisters reside in the same county (with $G_{i t}$ defined to be one for sisters living in the same county), as in

$$
E_{i t}^{*}=X_{i} \beta+E_{i t-1}^{\prime} G_{i t} \gamma+E_{i t-1}^{\prime} \cdot\left(1-G_{i t}\right) \cdot \delta+\epsilon_{i t} .
$$

The relative income model would suggest that the estimate of $\gamma$ should be positive and statistically significant, reflecting strong effects of sister's employment for women living close to each other, while the estimate of $\delta$ may be insignificant.

The estimates suggest that the estimated association with sister's employment is stronger for women living in the same county as their sister. The estimated coefficient of the sister's employment variable for those living in the same county is positive and statistically significant in both columns, with implied effects on the probability of employment that are larger than those in Table 1. In contrast, the estimated coefficients of the sister's employment variable for those not living in the same county are considerably closer to zero, and are not statistically significant. 
In addition, the t-statistics for the Jifferences between the two coefficients, reported in the last row of the table, exceed two.

The apparent stronger effest of sisters living in the same county could stem from similarities in local labor market :onditions, rather than stronger effects of relative income comparisons. As one means of examining this question, the specification reported in column (3) drops the local unemployment ra:e and husband unemployed variables. Although the first variable is generally at a more a:ggregate level than the county, if local labor market conditions underlie the findings in columns (1) and (2), then dropping these variables should strengthen the effect of sister's employment on a woman's own employment, for those living in the same county. The estimated coefficient of the sister employed/live in same county interaction (and the implied derivative) rises only sightly when the unemployment variables are omitted.

As an additional experiment, we used the full NLSY sample to randomly match up women living in the same cou:ty. ${ }^{30}$ If the relationship between the employment of the randomly matched women in these pairs is much weaker than that between sisters living in the same county, then unmeasured labor market conditions (or, alternatively, within-county similarities that might reflect the externalities discussed earlier) are less likely to underlie the relationships we find for sisters, and a relative income interpretation of the findings would be strengthened. ${ }^{31}$ Columns (4)-(6) present the : esults. The estimated coefficient on the matched woman's employment is never statistically significant, and is generally small and near zero, whether we use the matched woman's lagged (columns (4) and (5)) or current (column (6)) employment. Thus, in our view the stronger relationship between employment of sisters in the same county does not primarily reflect unobserved labor market conditions. ${ }^{32}$ Rather, in our view the results in Table 2 rule out at least : ome heterogeneity bias explanations of the association between 
sisters' employment and women's own employment, instead adding further support to the relative income hypothesis regarding women's employment decisions. ${ }^{33}$

\section{First difference estimates}

As an additional means of eliminating heterogeneity bias, we compute first-difference estimates that examine the effects of changes in sister's employment on changes in a woman's own employment. We estimate a model that is less restrictive than pure first differences, by allowing the effects of changes in sister's employment to vary depending on whether the sister became employed, or left employment. Because we regard our model more as an explanation of why some women choose to be employed, and others do not, than as an explanation of year-toyear transitions in employment, we are less inclined to test the model by looking at departures from the labor force, and instead want to focus on whether women's entry into the labor force is related to that of their sisters. Even then, we are less confident that our model explains transitions into employment. Because we allow asymmetric effects in the first-difference estimates, the fixed-effects logit model (Chamberlain, 1980) is inappropriate. We therefore use linear probability models. The linear probability model has heteroskedastic errors, but consistent standard errors can be obtained from White's (1980) procedure. It also has non-normal errors, but asymptotic inferences based on standard t-statistics are still valid if the right-hand-side variables are assumed to have a multivariate normal distribution (Maddalla, 1983).

The results are reported in Table 3. For purposes of comparison, the first two columns report linear probability estimates of the employment equations including lagged sister's employment, but excluding lagged own employment (since we will account for heterogeneity by differencing). The estimates indicates that women with employed sisters are about 25 percent more likely to be employed. The estimates in columns (3) and (4) simply include the differenced sister's employment variable (lagged). The positive coefficient implies that women 
are more likely to become employed after their sisters do, or to leave employment when their sisters do, although the estimate is not significant. The estimates in columns (5) and (6) allow for asymmetric effects, and indicate that there is a positive effect of the sister entering employment on the woman's own entry into employment, which is significant at the ten-percent level in both specifications. This is stronger evidence of a causal effect of a sister's employment on a woman's own employment.

\section{IV.5 Matching sisters and their sisters-in-law}

To this point, we have used a variety of econometric procedures to attempt to remove heterogeneity bias in the estimated relationship between women's employment and that of their sisters. An alternative approach is to match married sisters to their brothers in the NLSY, and then to estimate the relationship between women's employment and that of their sisters-in-law. Depending on patterns of assortative mating, common unobserved components may be much less important for sister/sister-in-law pairs, and hence estimates for such pairs should be less biased by heterogeneity than estimates for sister pairs. Becker (1981) derives the theoretical conditions for positive or negative assortative mating on given traits. The general result is that we expect negative sorting on wages (as marriage markets generate a sex-based division of labor), and positive sorting on non-wage characteristics. Behrman, et al. (1994) use data on twins and their spouses to study explicitly the relationship between earnings endowments (i.e., unobserved ability that affects earnings) of men and schooling of their wives. They find evidence of a negative relationship, which they interpret as evidence of negative sorting on wage-related characteristics, because schooling is positively related to the propensity to work. Assuming that brothers and sisters have positively correlated unobserved propensities to work (because of similarities in motivation or ability), then this negative sorting suggests that the propensities to work of sisters and their sisters-in-law should be negatively correlated, or at least less positively 
correlated than for sister/sister pairs. ${ }^{34}$ Thus, if the results for sister/sister-in-law pairs parallel those for sister pairs, we would less inclined to attribute the results to heterogeneity bias.

Results paralleling those in Tables 1 and 2 are reported in Table 4, for 305 pairs of married sisters and their sisters-in-law. The results are very similar to those for sister pairs. In columns (1) and (2), where we do not distinguish between sister/sister-in-law pairs on the basis of residence in the same county, the estimated coefficient on sister-in-law's employment is positive, and statistically significant in column (2). In columns (3) and (4), where we distinguish by residence in the same county, the estimated coefficient of sister-in-law's employment is always positive and significant for pairs residing in the same county. These results bolster our confidence that the estimated relationship between employment of sisters does not solely reflect heterogeneity.

\section{IV.6 Currently married women}

The theoretical model described in Section III refers to married couples. The preceding tables are based on estimates that also include divorced, separated, or widowed women, and married women with absent spouses. This was done partly to boost sample sizes, partly because we are interested in feedback effects that stem from sources other than relative income concerns, such as externalities, and partly because there is no reason to believe that relative income concerns are relevant only for currently married women. To gauge the sensitivity of the results to the inclusion of once-married women, Table 5 reports estimates of our key specifications for the subset of currently married sisters. Columns (1) and (2) report estimates of the employment equations including sister's employment. ${ }^{35}$ Whether lagged own employment is excluded (column (1)) or included (column (2)), the estimated coefficients of sister's employment are positive and statistically significant, and the implied effects are larger than in Table 1. In column (3), we distinguish the estimate based on whether or not sisters live in the 
same county. For those living in the same county, the estimated coefficient of sister's

employment is positive and significant. In contrast to the results for the larger sample, though, in this case the estimated coefficient is also significant, although smaller, for sisters not residing in the same county. Columns (4) and (5) repeat the first difference experiment. In column (4), the evidence is stronger than for the larger sample, as the estimated coefficient on the change in sister's employment is larger, and significant at the ten-percent level. The results allowing asymmetric effects, in column (5), differ in that the point estimate for sister left employment is now larger (in absolute value). Finally, columns (6) and (7) repeat the sister/sister-in-law experiment for currently married women. The results are very similar to those for the full sample in Table 4. We conclude, then, that the results from the previous tables hold up in the subsample of currently married women.

\section{IV.7 Looking at relative income of husbands}

Finally, we turn to evidence on the test that is directly motivated by the model as it was set up in Section III, and report estimates of equation (IV.3). In addition to providing a more direct test of the model, this experiment is much less likely to be contaminated by heterogeneity bias, because we are no longer looking at the same variable (employment) of women and their sisters. A disadvantage of this test is that it relates to the specific version of the model discussed in Section III. In addition, once we split the sample into those with employed and non-employed sisters, the remaining samples are quite small.

The results are reported in Table 6. Panel A reports results for the sample of women whose sisters are not employed. In columns (1)-(4), for logit estimates of the employment equation, the estimated effect of the husbands' relative income variable is positive, as predicted.

The estimated coefficient is marginally significant in two of the specifications, and significant at the five-percent level in a third. Panel B reports results for the sample of women whose sisters 
are employed. In all four columns the estimated effect is negative, also as predicted, and the estimated coefficients are significant or nearly so at the ten-percent level. ${ }^{36}$ Overall, then, the sign patterns are consistent with the predictions of the specific model depicted in Figure 2, although the evidence is statistically significant only in relationship to region $\mathbf{R}$.

Finally, we consider the possibility that the results in Table 6 stem from life-cycle developments that bias the results in the direction of the predicted effects. In particular, in Panel A we might imagine that when women are younger than their sisters, they may still be employed, while their sisters are non-employed, in part because their husbands have attained higher earnings. Thus, there may be positive upward bias. In Panel B, the opposite might hold. Women who are older than their sisters might be non-employed while their sisters are employed, in part because their husbands earn more, creating negative bias. We explore this in two ways. First, in column (5) we add sister's age as a control variable. In Panel A, the effect of sister's husband's relative income falls slightly. In Panel B, in contrast, the effect strengthens, becoming significant at the ten-percent level. As an alternative approach, in column (6) we allow different effects of the relative income variable depending on whether the respondent was older or younger than her sister. In Panel $\mathrm{A}$, the estimated coefficients are positive in both cases, although larger when the respondent is younger than her sister, partly consistent with this bias story. In Panel B, the estimated coefficient is significant and negative when the respondent is younger than her sister, rather than older. This result is more difficult to explain as stemming from life-cycle developments, and in our view bolsters the evidence in Panel B in favor of the relative income model.

\section{Conclusions}

The striking rise in the employment of married women can be partially but not fully explained by a neoclassical model including variables capturing individual women's market 
opportunities, home productivity, other sources of income, and taste shifters. In this paper, we propose a "relative income ' model of women's employment decisions which implies that, in addition to the variables identified by the neoclassical model, the decision of other women to enter employment may aft :ct a woman's own decisions. We test the prediction of this model that a woman's employme it decision depends on that of her peers, ceteris paribus. In particular. we look at the interrelatio sship between the employment decisions of sisters. Consistent with the model, we find that there is a strong statistical association between the employment decisions of sisters. Furthermore, thi - association does not appear to arise from family-specific heterogeneity in unobserved factors aff $\mathrm{t}$ cting employment decisions, but instead appears to reflect a causal effect. Our estimates suggest that, all else the same, women whose sisters worked in the previous year are about 10 to 15 percent more likely to work than those whose sisters did not work, for sisters living in close proximity to one another. We also look at evidence on whether women's employment re ponds to the income of their husbands relative to that of their sisters' husbands, as the model vould predict. This evidence is partly consistent with the specific form of the model that we pre sent in the paper. In particular, women with non-working sisters are about 15 percent more likely to be employed if their husbands earn less than their sisters' husbands, a result consi tent with women's employment decisions being partly driven by relative income concerns. In our view, the weight of the evidence, combined with the theoretical results, suggests that re:ative income effects on women's employment decisions may help to explain why married $w$.men's employment rose faster than can be explained by the standard neoclassical model. 


\section{References}

Akerlof, George A. 1982. "Labor Contracts as Partial Gift Exchange." Quarterly Journal of Economics 97: 543-69.

Becker, Gary S. 1981. A Treatise on the Family (Cambridge: Harvard University Press). 1991. "A Note on Restaurant Pricing and Other Examples of Social Influences on Price." Journal of Political Economy 99(5): 1109-16.

Behrman, Jere R., Mark R. Rosenzweig, and Paul Taubman. "Endowments and the Allocation of Schooling in the Family and in the Marriage Market: The Twins Experiment." Journal of Political Economy, 102: 1131-74.

Bowen, William G., and T. Aldrich Finegan. 1969. The Economics of Labor Force Participation (Princeton: Princeton University Press).

Cain, Glen. 1966. Married Women in the Labor Force (Chicago: University of Chicago Press).

Chamberlain, Gary. 1980. "Analysis of Covariance with Qualitative Data." Review of Economic Studies 47: 225-38.

Clark, Kim, and Lawrence H. Summers. 1979. "Labor Market Dynamics and Unemployment: A Reconsideration." Brookings Paper on Economic Activity 13-60.

Cole, Harold, George Mailath, and Andrew Postlewaite. 1992. "Social Norms, Savings Behavior and Growth," Journal of Political Economy 100: 1092-125.

Duesenberry, James S. 1949). Income, Savings, and the Theory of Consumer Behavior (Cambridge, MA: Harvard University Press, Cambridge).

Frank, Robert H. 1985. Choosing the Right Pond: Human Behavior and the Quest for Status (New York: Oxford University Press).

Geronimus, Arline T., and Sanders Korenman. 1993. "The Costs of Teenage Childbearing: Evidence and Interpretation." Demography 30(2): 281-90.

Goldin, Claudia D. 1991. "The Role of World War II in the Rise of Women's Employment." American Economic Review 81(4): 741-56.

1990. Understanding the Gender Gap: An Economic History of American Women (New York: Oxford University Press).

Heckman, James J. 1981. "Heterogeneity and State Dependence." In Sherwin Rosen, Ed., Studies in Labor Markets (Chicago: University of Chicago Press), pp. 91-139.

. 1978. "Dummy Endogenous Variables in a Simultaneous Equation System."

Econometrica 46(6): 931-59. 
Hoffman, Saul D., E. Michael Foster, and Frank F. Furstenberg. 1993. "Reevaluating the Costs of Teenage Childbearing: Response to Geronimus and Korenman." Demography 30(2): 291-5.

Maddalla, G. S. 1983. Limited-Dependent and Qualitative Variables in Econometrics (Cambridge, UK: Cambridge University Press).

Mincer, Jacob. 1962. "Labor Force Participation of Married Women: A Study of Labor Supply." In H. Gregg Lewis, Ed. Aspects of Labor Economics (Princeton: Princeton University Press), pp. 63-97.

Rees, Albert, and Wayne Gray. 1982. "Family Effects in Youth Employment." In R. Freeman and D. Wise, Eds. The Youth Labor Market Problem: Its Nature, Causes, and Consequences (Chicago: The University of Chicago Press), pp. 453-64.

Smith, James P., and Michael P. Ward. 1985. "Time-Series Growth in the Female Labor Force." Journal of Labor Economics 3(1, Supp.): S59-S90.

Summers, Lawrence H. 1988. "Relative Wages, Efficiency Wages, and Keynesian Unemployment." American Economic Review 78(2): 383-88.

White, Halbert. 1980. "A Heteroskedasticity-Consistent Covariance Matrix and a Direct Test for Heteroskedasticity." Econometrica 48(3): 721-46.

Winship, Christopher. 1982. "Comment on Family Effects in Youth Employment." In R. Freeman and D. Wise, Eds. The Youth Labor Market Problem: Its Nature, Causes, and Consequences (Chicago: The University of Chicago Press), pp. 465-68. 


\section{Endnotes}

1. For evidence on trends in women's employment extending back further, see Goldin (1990).

2. These increases were concentrated among married women, as single women had high employment rates at the beginning of the century. Participation rates among black women display similar trends to those of white women, but started at much higher levels, and declined during the Depression (Goldin, 1990).

3. Cain (1966) reports very similar results using a 1950 cross-city regression, and predicting changes over the period 1939-1957.

4. Of course real wage growth did not stagnate at all points in the wage distribution, so participation could have continued to rise despite constant mean or median real wages.

5. For this reason, Smith and Ward's predictions of women's employment growth do not condition on changes in fertility.

6. Bowen and Finegan (1969) also discount the importance of the war per se, concluding that "the increases in the participation of married women which took place between 1940 and 1950 need not be explained primarily in terms of the changes in social attitudes brought about by wartime experiences" (pp. 224-5). This is because in their analysis of the ability of cross-sectional (cross-city) participation regressions to explain changes in participation over various decades, standard income, wage, and shadow wage variables are particularly powerful predictors for the 1940-1950 period. Cain (1966) reached a similar conclusion, focusing in particular on the decrease in family income owing to drafting of husbands, and the decline in the demand for women's household services.

7. Goldin offers two reasons why the uncompensated wage effect may have fallen. First, for women work has become less solely a way to earn money, and more a means of seeking purpose and status in life. Thus, the decision to work has become less responsive to the wage. Second, with women gaining access to better jobs, work at one point in the life-cycle may increase earnings at other points in the life-cycle via, for example, training. This also would diminish the response of employment to wages.

8. We will discuss below other interpretations and determinants of this opportunity cost.

9. For reasons explained in Section IV, in the empirical work we focus on employment, not participation. Thus, although employment depends on a labor supply decision as well as a labor demand decision--in contrast, perhaps, to participation--in this section we make reference to women's employment decisions.

10. Note that we are showing the proportion of women at ( $\left.b^{\prime}, a^{\prime}\right)$ who work, not the difference between the proportion of those at working $\left(\mathbf{b}^{\prime}, \mathbf{a}^{\prime}\right)$ vs. those working at $(\mathbf{b}, \mathbf{a})$.

11. This result does not speak to the question raised in Section II regarding changes over time in cross-section estimates of the effects of changes in women's and men's wages. Without further restrictions on functional forms, our model makes no predictions as to how the "cross-section effects" would vary as, for example, the proportion of women working 
rises.

12. Cole, Mailath and Postlewaite (1992) analyze a model in which no agents care directly about their relative income position, but in equilibrium relative income matters because nonmarket decisions (children's marriage prospects in that model) might be affected by relative income position. They discuss in more detail how reduced form utility functions may depend on relative wealth when direct utility functions do not.

13. A model in a similar spirit is provided in Becker (1991), in which because of social interactions, individual demands for some goods depend on the aggregate market demand. In our case, women's labor supply depends to some extent on the labor supply of other women.

14. This type of phenomenon could, in principle, explain why the neoclassical model falls short of explaining the rise in married women's labor force participation in the latter part of this century.

15. We focus on employment rather than labor force participation because the latter is a somewhat ambiguous concept, hinging on whether or not one is looking for work. This definitional ambiguity is reflected in the empirical evidence showing that many women leave the unemployed state (regarded as in the labor force) because of discouragement regarding finding employment (Clark and Summers, 1979). Also, we would expect employment, rather than participation per se, to drive relative income.

16. It turns out that, for the full sample, lagged sister's employment is more strongly related to own employment than is contemporaneous sister's employment.

17. Note that it is the dummy variable representing the sister's employment, rather than the latent variable underlying $E^{\prime}$, that enters the equation. Heckman (1978) discusses models with mixed latent variable and dummy variable structures. He identifies cases in which sensible statistical models do not exist, as when the dummy variable for an event enters into the equation for the latent variable underlying that dummy variable. However, this is not the case here, since it is the sister's dummy variable that enters the equation for the woman's unobserved propensity to work.

18. In addition, if the true value of $\gamma$ is positive, there may be upward endogeneity bias in the estimate of $\gamma$ because there is a parallel equation to (IV.2) for the other sister. However, endogeneity cannot alone explain a positive estimate of $\gamma$.

19. We are grateful to Steve Matusz for pointing this out.

20. For the relative income measure, the contemporaneous value is more strongly related to employment than is the lagged value.

21. Sisters are identified in the NLSY sample if they were coresident in surveyed households in 1979. The issue of biases from this nonrandom selection of the sample has been raised in research using sister data to estimate the socioeconomic effects of teenage childbearing (Hoffman, et al., 1993; Geronimus and Korenman, 1993). However, this concern is less important in the current context for two reasons. First, the issue originally arose for the NLS Young Women's sample, in which sisters had to be coresident between ages 14 and 24. 
There may be biases from this selection rule for 22-24 year-olds, among whom those remaining at home are likely to be nonrandom sample (Hoffman, et al., 1993). In contrast, the NLSY age range was 14-21 in 1979. Second, the teenage childbearing literature is concerned with outcomes that are directly related to household formation, for which selection rules related to household structure seem most likely to create problems.

22. For some of the empirical analysis, we require three observations per woman.

23. Husband's income is equal to zero for women who are divorced, widowed, separated, or have an absent spouse. (The same is true for the husband's unemployment variable described below.) Data on child support and alimony were not available for many years in the NLSY, and therefore could not be used.

24. We chose this rather crude procedure to avoid having to impute wages for non-working women. Without knowing the form of the employment equation (which is the issue this paper addresses), we cannot confidently impute wages for non-working women. Also, to the extent that education provides a less transitory measure of earnings power than the current period wage, its coefficient may more closely reflect cross-sectional variation in women's employment choices attributable to variations in the height of wage profiles, rather than intertemporal substitution. This same concern was reflected in Mincer's (1962) use of SMSA averages to estimate cross-section employment equations for married women.

25. For those residing in an SMSA, this is the SMSA unemployment rate. For those not residing in an SMSA, this is the unemployment rate for the non-SMSA population of the state of residence.

26. This is the only unemployment measure for the husband that is consistently available across the years in the NLSY.

27. These results parallel those in Rees and Gray (1982).

28. We also tried controlling for sister's education, as a means of capturing common family background. The estimated coefficient of sister's education was always near zero and insignificant, and had no effect on the other results. Of course, the inclusion of a woman's own education may already control for that part of family background that is related to education.

29. One might also interpret a finding that sister's employment is more important when the sister lives nearby as evidence of feedback effects on employment from the types of externalities resulting from women's employment decisions that were discussed in the theoretical section.

30. Details regarding the sample construction are provided in the footnote to Table 2 .

31. Ken Wolpin suggested this experiment.

32. Another possibility is that employment of sisters is positively related because one helps the other find a job. Evidence in Winship (1982) suggests that about 5-10 percent of people over age 20 find jobs through the help of a relative (although there is no evidence on whether the relative was a sibling). In fact, this evidence was offered as a potential explanation of 
the correlation between employment of siblings found by Rees and Gray (1982). The NLSY contains data on methods used to find jobs, but only for a few years, and only for workers who were unemploy zd.

33. To this point, one could claim that in the specifications excluding lagged employment, we have not adequa ely allowed for the possibility of a common family component in the employment equatic $n$ error, and hence may be understating our standard errors. To examine this issue, we reestimated the models in Tables 1 and 2 using a sample of one sibling randomly selected from each pair. We obtained very similar estimates and significance levels.

34. By the same ar șument, these propensities to work should also be less strongly positively correlated than for wives of brothers.

35. For this subsariple, the effect of current sister's employment was stronger than that of lagged sister's emf loyment.

36. If women's en ployment is negatively related to their husbands' income, either because husband's income esponds endogenously to women's employment, or because of negative assortative mating on wage-related characteristics, there may be positive upward endogeneity bias in the estimat :d coefficient of the relative income variable (since husband's income appears in the der.sminator). This suggests that in Panel B there may be some bias against the hypothesis bei ig tested, and in Panel A some bias in its favor. 
Figure 1

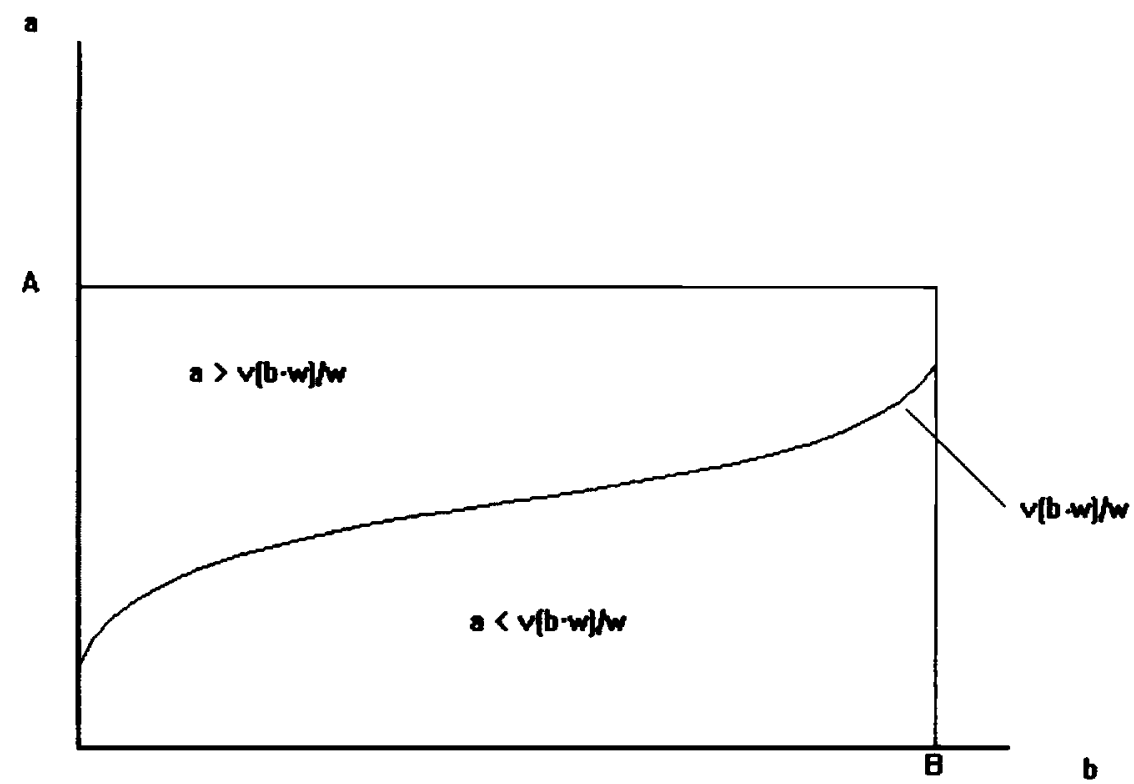




$$
1
$$


Figure 3

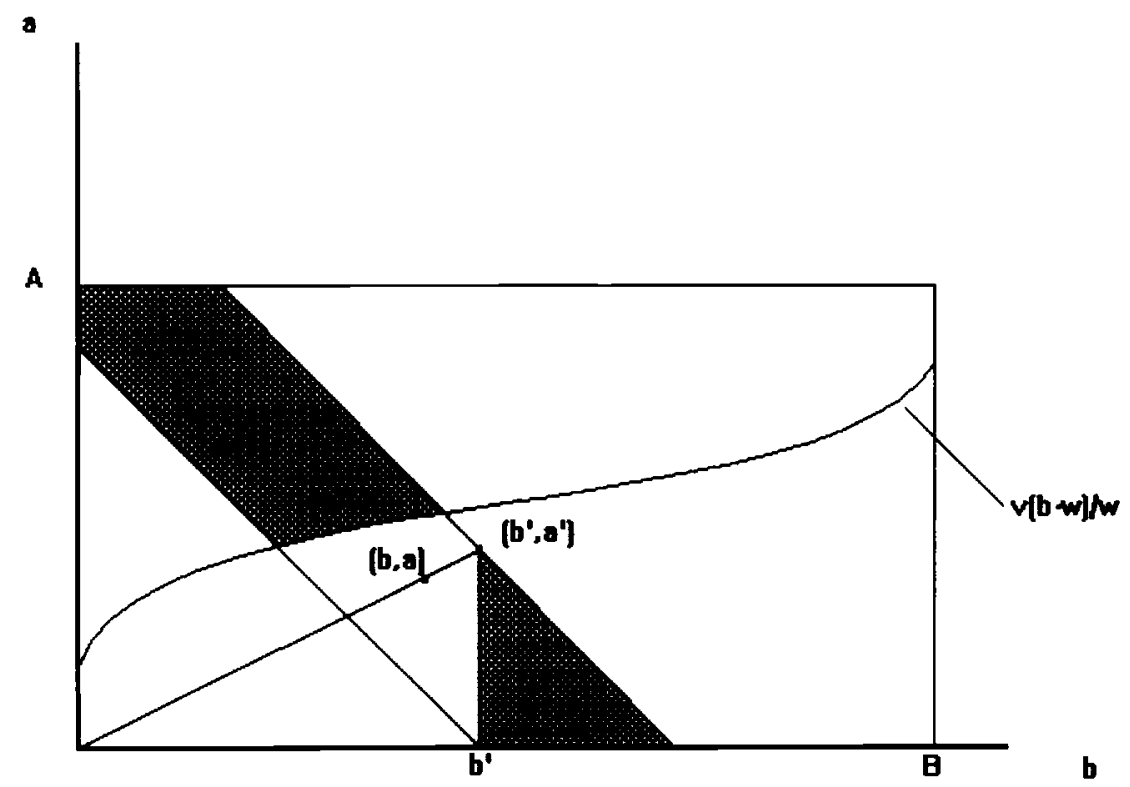




$$
7
$$




\begin{tabular}{|c|c|c|c|c|c|c|}
\hline $\begin{array}{l}\text { Sister employed, } \\
\text { lagged one year }\end{array}$ & $\begin{array}{l}(1) \\
\ldots\end{array}$ & $\begin{array}{l}(2) \\
\ldots\end{array}$ & $\begin{array}{l}(3) \\
1.059 \\
(.264) \\
{[.196]}\end{array}$ & $\begin{array}{l}(4) \\
1.080 \\
(.299) \\
{[.165]}\end{array}$ & $\begin{array}{l}(5) \\
.765 \\
(.299) \\
{[.113]}\end{array}$ & $\begin{array}{r}(6) \\
.804 \\
(.339) \\
{[.097]}\end{array}$ \\
\hline $\begin{array}{l}\text { Own employment, lagged } \\
\text { one year }\end{array}$ & $\cdots$ & .. & $\cdots$ & $\ldots$ & $\begin{array}{l}2.184 \\
(.293) \\
{[.344]}\end{array}$ & $\begin{array}{l}2.471 \\
(.347) \\
{[.298]}\end{array}$ \\
\hline Husband's income $/ \$ 1000$ & $\begin{array}{l}-.010 \\
(.009)\end{array}$ & $\begin{array}{l}-.030 \\
(.011)\end{array}$ & $\begin{array}{l}-.012 \\
(.009)\end{array}$ & $\begin{array}{l}-.029 \\
(.011)\end{array}$ & $\begin{array}{l}-.011 \\
(.010)\end{array}$ & $\begin{array}{l}-.029 \\
(.013)\end{array}$ \\
\hline Other income $/ \$ 1000$ & $\begin{array}{l}-.112 \\
(.045)\end{array}$ & $\begin{array}{l}-.095 \\
(.055)\end{array}$ & $\begin{array}{l}-.116 \\
(.046)\end{array}$ & $\begin{array}{l}-.094 \\
(.056)\end{array}$ & $\begin{array}{l}-.107 \\
(.047)\end{array}$ & $\begin{array}{l}-.097 \\
(.048)\end{array}$ \\
\hline Years of education & $\begin{array}{l}.317 \\
(.076)\end{array}$ & $\begin{array}{l}.193 \\
(.087)\end{array}$ & $\begin{array}{l}.293 \\
(.075)\end{array}$ & $\begin{array}{l}.177 \\
(.085)\end{array}$ & $\begin{array}{l}.246 \\
(.084)\end{array}$ & $\begin{array}{l}.135 \\
(.100)\end{array}$ \\
\hline Local unemployment rate & $\begin{array}{l}-.141 \\
(.039)\end{array}$ & $\begin{array}{l}-.126 \\
(.051)\end{array}$ & $\begin{array}{l}-.131 \\
(.040)\end{array}$ & $\begin{array}{l}-.119 \\
(.052)\end{array}$ & $\begin{array}{l}-.115 \\
(.045)\end{array}$ & $\begin{array}{l}-.104 \\
(.059)\end{array}$ \\
\hline Black & $\ldots$ & $\begin{array}{l}.517 \\
(.457)\end{array}$ & $\ldots$ & $\begin{array}{l}.521 \\
(.468)\end{array}$ & $\ldots$ & $\begin{array}{l}.429 \\
(.510)\end{array}$ \\
\hline Hispanic & $\cdots$ & $\begin{array}{l}-.451 \\
(.384)\end{array}$ & $\cdots$ & $\begin{array}{l}-.374 \\
(.395)\end{array}$ & $\ldots$ & $\begin{array}{l}-.526 \\
(.447)\end{array}$ \\
\hline $\begin{array}{l}\text { Husband unemployed } \\
\text { during year }\end{array}$ & $\ldots$ & $\begin{array}{r}-1.028 \\
(.570)\end{array}$ & $\ldots$ & $\begin{array}{r}-1.034 \\
(.585)\end{array}$ & $\ldots$ & $\begin{array}{l}-.880 \\
(.725)\end{array}$ \\
\hline $\begin{array}{l}\text { Divorced, separated, } \\
\text { widowed, or spouse absent }\end{array}$ & $\ldots$ & $\begin{array}{l}-.634 \\
(.402)\end{array}$ & $\cdots$ & $\begin{array}{l}-.484 \\
(.415)\end{array}$ & $\ldots$ & $\begin{array}{l}-.224 \\
(.476)\end{array}$ \\
\hline Number of children & $\ldots$ & $\begin{array}{l}-.681 \\
(.162)\end{array}$ & $\ldots$ & $\begin{array}{l}-.704 \\
(.168)\end{array}$ & $\ldots$ & $\begin{array}{l}-.738 \\
(.196)\end{array}$ \\
\hline $\begin{array}{l}\text { Number of children aged } \\
\text { one year or less }\end{array}$ & $\ldots$ & $\begin{array}{l}-.806 \\
(.331)\end{array}$ & $\ldots$ & $\begin{array}{l}-.764 \\
(.341)\end{array}$ & $\ldots$ & $\begin{array}{r}-1.033 \\
(.398)\end{array}$ \\
\hline $\begin{array}{l}\text { Regional dummy variables (3), } \\
\text { age, and residence in an SMSA } \\
\text { included }\end{array}$ & No & Yes & Yes & No & Yes & Yes \\
\hline Log-likelihood & -198.2 & -168.6 & -190.1 & -161.9 & -159.7 & -132.0 \\
\hline
\end{tabular}

1. Asymptotic standard errors are reported in parentheses. Estimates are based on a sample of 173 sister pairs. The sample was constructed from the first two observations on each woman in the non-military sample provided: i) she and her sister were out of school; ii) she and her sister left school within three calendar years of each other; iii) she and her sister were married by the time of the first observation; and iv) data on the variables used were available for both years. For this table, data from the second year on each woman are used (because we include lagged own employment). Partial derivatives with respect to sister's employment, evaluated at the sample means, are reported in square brackets. All income measures are deflated by the CPI. The husband's income variables equal 0 for not currently married women.

2. When the lagged and contemporaneous values were entered in the same specification, only the lagged value had an estimated coefficient that was statistically significant. 
Table 2

Logit Estimates of Employment Equations, Using Sister's Employment Interacted with Geographical Proximity ${ }^{1}$

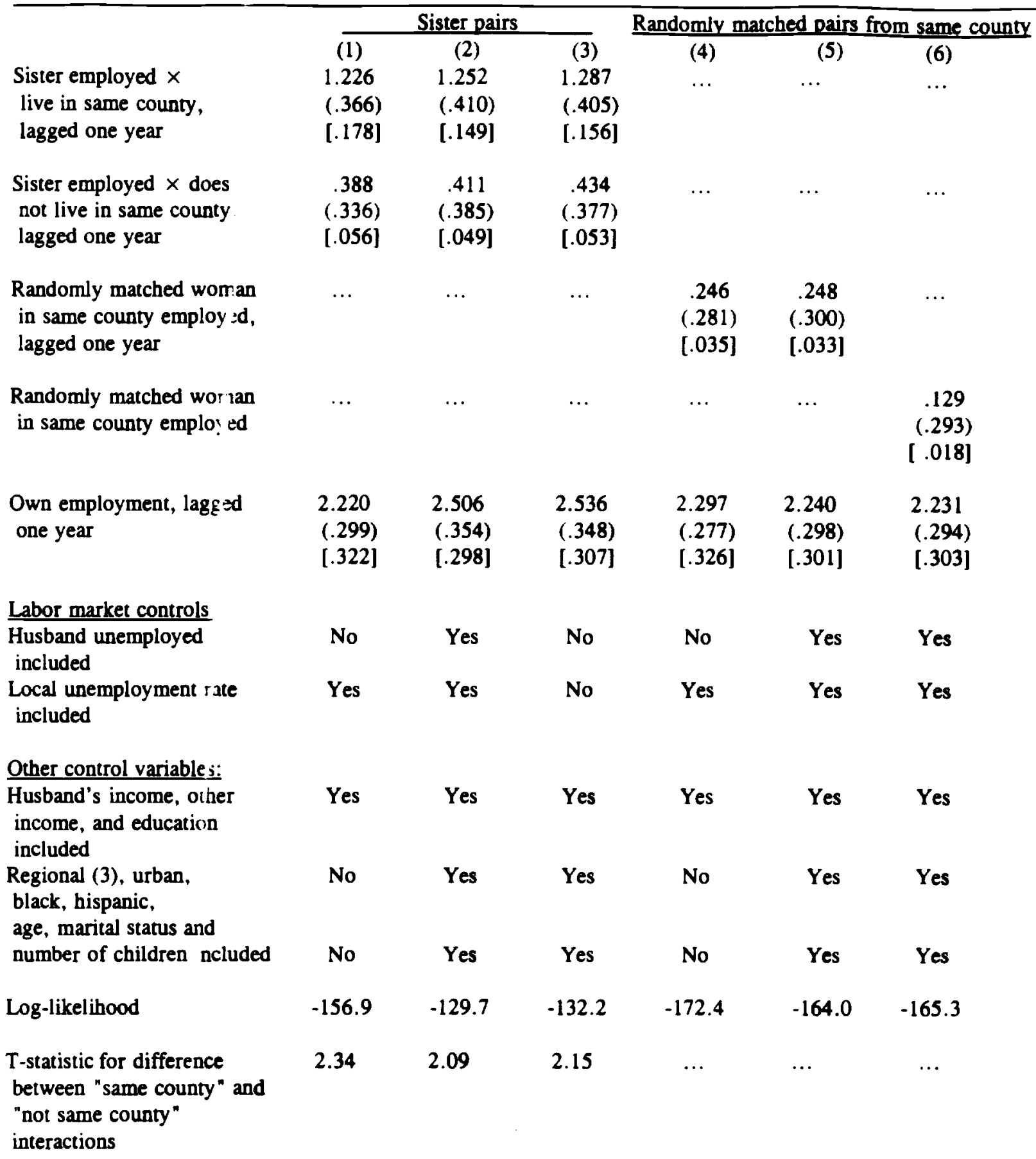

1. See notes to Table 1 for details. The "live in same county" dummy variable is defined to equal one when the sisters lived in the same county for bo $h$ years for which data are used. Estimates in columns (4)-(6) on a sample of 193 pairs of women randomly matched from the sume county. The sample selection criteria are the same as those for the women used in the other tables. Pairs are restricted to be the same race, and multiple pairs from the same county are not used. Women in these pairs are restricted to those who did not change their county of residence over the two years for which data on each woman are used. 
Table 3

Linear Probability Estimates of Employment Equations, First Difference Estimates

\begin{tabular}{|c|c|c|c|c|c|c|}
\hline & \multicolumn{2}{|c|}{ OLS } & \multicolumn{4}{|c|}{ First Difference } \\
\hline & (1) & (2) & (3) & (4) & (5) & (6) \\
\hline $\begin{array}{l}\text { Sister employed, } \\
\text { lagged one year }\end{array}$ & $\begin{array}{l}.253 \\
(.062)\end{array}$ & $\begin{array}{l}.266 \\
(.059)\end{array}$ & $\cdots$ & $\cdots$ & $\ldots$ & $\ldots$ \\
\hline $\begin{array}{l}\Delta \text { Sister employed, } \\
\text { lagged one }\end{array}$ & $\cdots$ & $\cdots$ & $\begin{array}{l}.048 \\
(.048)\end{array}$ & $\begin{array}{l}.062 \\
(.049)\end{array}$ & $\cdots$ & $\cdots$ \\
\hline $\begin{array}{l}\text { Sister entered } \\
\text { employment, } \\
\text { lagged one year }\end{array}$ & $\cdots$ & $\cdots$ & $\cdots$ & $\cdots$ & $\begin{array}{l}.124 \\
(.074)\end{array}$ & $\begin{array}{l}.135 \\
(.073)\end{array}$ \\
\hline $\begin{array}{l}\text { Sister left } \\
\text { employment, } \\
\text { lagged one year }\end{array}$ & $\cdots$ & $\cdots$ & $\cdots$ & $\cdots$ & $\begin{array}{l}.011 \\
(.064)\end{array}$ & $\begin{array}{l}-.002 \\
(.070)\end{array}$ \\
\hline $\begin{array}{l}\text { Husband unemployed } \\
\text { included }\end{array}$ & No & Yes & No & No & Yes & Yes \\
\hline $\begin{array}{l}\text { Local unemployment rate } \\
\text { included }\end{array}$ & Yes & Yes & No & Yes & Yes & Yes \\
\hline \multicolumn{7}{|l|}{ Control variables: } \\
\hline $\begin{array}{l}\text { Husband's income, other } \\
\text { income, and education } \\
\text { included }\end{array}$ & Yes & Yes & Yes & Yes & Yes & Yes \\
\hline Other controls included ${ }^{2}$ & No & Yes & No & Yes & No & Yes \\
\hline \multicolumn{7}{|c|}{$\begin{array}{l}\text { 1. The sample used in this table requires three observations per person, since we form the first difference of lagged sister's } \\
\text { employment. The sample was constructed from the first three observations on each woman in the non-military sample provided: i) } \\
\text { she and her sister were out of school; ii) she and her sister left school within three calendar years of each other; iii) she and her sister } \\
\text { were married by the time of the first observation; and iv) data on the variables used were available for all three years. This yielded } \\
\text { a sample of } 270 \text { women, consisting of sisters in } 135 \text { sibling pairs, from the NLSY sample. Data from the third year on each woman } \\
\text { are used (because we include the changes in the sister's variables lagged once). Standard errors are reported in parentheses. For } \\
\text { linear probability models, standard t-tests are valid if the explanatory variables have a multivariate normal distribution. In the linear } \\
\text { probability model the estimated coefficients measure the partial derivative of the corresponding variable on the probability of the } \\
\text { outcome. Coefficients are approximately one-quarter those of the logit model (Maddalla, 1983). Robust standard errors are reported } \\
\text { (White, 1980). }\end{array}$} \\
\hline
\end{tabular}

2. These are the control variables in columns (2), (4), and (6) of Table 1. 
Sister-in-law employed

Sister-in-law employed $x$ live in same county

Sister-in-law employed $x$ does not live in same county

Own employment, lagged one year

Log-likelihood$$
\text { . }
$$

T-statistic for difference

between "same county" and

"not same county"

interactions

Control variables:

Husband's income, other income, education, and local unemployment rate Other control variables ${ }^{2}$
[.072]

$$
-91.8
$$

(3)

$\begin{array}{llll}\text { Yes } & \text { Yes } & \text { Yes } & \text { Yes } \\ \text { No } & \text { Yes } & \text { No } & \text { Yes }\end{array}$

1. The sample used in this table was constructed by matching sister-brother pairs in the NLSY, and then merging information on the sister with the employment status of the brother's wife (i.e., the woman's sister-in-law). The other rules for selection in the sample follow those used for the sister-sister pairs as much as possible; for some variables information on the sister-in-law is not available. This led to a sample of 305 pairs of sisters and their sisters-in-law. In columns (3) and (4), the "live in same county "dummy variable is defined to equal one when the sisters lived in the same county for both years for which data are used, as in Table 2 . The only difference compared with Table 2 is that results using the sister-in-law's current employment status are reported; the estimated coefficients of lagged employment (interacted with lived in same county or not) were generally not statistically significant, although the signs agreed with those reported in this table.

2. These are the control variables in columns (2), (4), and (6) of Table 1. 
Logit estimates:

Sister (-in-law) employed

\begin{tabular}{|c|c|c|c|c|c|c|c|}
\hline & \multicolumn{7}{|c|}{ Corresponding Specification ${ }^{2}$} \\
\hline & $\begin{array}{l}\text { Table 1, } \\
\text { Col. (4) } \\
\text { (1) }\end{array}$ & $\begin{array}{l}\text { Table 1, } \\
\text { Col. (6) } \\
\text { (2) }\end{array}$ & $\begin{array}{l}\text { Table 2, } \\
\text { Col. (2) } \\
\text { (3) }\end{array}$ & $\begin{array}{c}\text { Table 3, } \\
\text { Col. (4) } \\
\text { (4) }\end{array}$ & $\begin{array}{c}\text { Table 3, } \\
\text { Col. (6) } \\
\text { (5) }\end{array}$ & $\begin{array}{c}\text { Table 4, } \\
\text { Col. (2) } \\
\text { (6) }\end{array}$ & $\begin{array}{l}\text { Table 4, } \\
\text { Col. (4) } \\
\text { (7) }\end{array}$ \\
\hline \multicolumn{8}{|l|}{ Logit estimates: } \\
\hline Sister (-in-law) employed & $\begin{array}{l}1.459 \\
(.359) \\
{[.207]}\end{array}$ & $\begin{array}{l}1.326 \\
(.432) \\
{[.135]}\end{array}$ & $\cdots$ & $\ldots$ & $\ldots$ & $\begin{array}{l}.750 \\
(.493) \\
{[.059]}\end{array}$ & $\ldots$ \\
\hline $\begin{array}{l}\text { Sister (-in-law) employed } \times \\
\text { live in same county }\end{array}$ & $\ldots$ & $\cdots$ & $\begin{array}{l}1.505 \\
(.513) \\
{[.153]}\end{array}$ & $\cdots$ & $\cdots$ & $\cdots$ & $\begin{array}{l}1.609 \\
(.688) \\
{[.123]}\end{array}$ \\
\hline $\begin{array}{l}\text { Sister (-in-law) employed } \times \\
\text { does not live in } \\
\text { same county }\end{array}$ & $\ldots$ & .. & $\begin{array}{l}1.173 \\
(.486) \\
{[.119]}\end{array}$ & ... & $\ldots$ & $\cdots$ & $\begin{array}{l}.202 \\
(.551) \\
{[.015]}\end{array}$ \\
\hline \multicolumn{8}{|l|}{ Linear probability estimates: } \\
\hline$\Delta$ Sister employed & $\cdots$ & $\ldots$ & $\ldots$ & $\begin{array}{l}.116 \\
(.069)\end{array}$ & $\cdots$ & $\cdots$ & $\cdots$ \\
\hline Sister entered employment & $\ldots$ & $\cdots$ & $\cdots$ & $\ldots$ & $\begin{array}{l}.078 \\
(.094)\end{array}$ & $\cdots$ & $\cdots$ \\
\hline Sister left employment & ... & $\cdots$ & $\ldots$ & $\cdots$ & $\begin{array}{l}-.142 \\
(.100)\end{array}$ & $\cdots$ & $\cdots$ \\
\hline
\end{tabular}

Corresponding Specification ${ }^{2}$

1. For columns (1)-(5), because the sample was relatively small, we redrew a sample using the criteria described in the footnotes to Table 1, but conditioning on current marriage, yielding 140 sister pairs. For the currently married subsample, in contrast to the results corresponding to columns (3)-(6) of Table 1, when lagged and contemporaneous values of sister's employment were entered in the same specification, only the contemporaneous value had an estimated coefficient that was statistically significant. Consequently. for the currently married subsample the "sister employed" variables are defined for contemporaneous rather than lagged values. In columns (6) and (7), the sample used in Table 4 is restricted to the 256 sister/sister-in-law pairs in which the respondent is currently married.

2. The only difference relative to the indicated specifications is that the marital status control is dropped. 
A. Sister Non-Employed $(N=90)$

(1)

(3)

(4)

(5)

(6)

Sister's husband's
income greater than
own husband's
income
$\times$ Respondent
older than sister
$\times$ Respondent
younger than sister

.778

(.513)

.477

(.607)

2.585

1.624

1.554

[.196]

[.146]

(1.029)

(1.087)

(1.078)

[.254]

[.158]

[.126]

...

$\cdots$

1.305

(1.154)

[.215]

2.614

(1.763)

[.215]

B. Sister Employed $(N=190)$

$\begin{array}{lccccc}\text { Sister's husband's } & -.627 & -.938 & -.787 & -1.051 & -1.205 \\ \text { income greater than } & (.430) & (.525) & (.528) & (.652) & (.680) \\ \text { own husband's } & {[-.095]} & {[-.104]} & {[-.089]} & {[-.085]} & {[-.097]} \\ \text { income } & & & & & \end{array}$

$\times$ Respondent

older than sister

$\begin{array}{llllll}\ldots & \ldots & \ldots & \ldots & \ldots & -.216\end{array}$

$(.802)$

$[-.017]$

$\times$ Respondent

younger than sister

- $\quad \cdots \quad \ldots$

$-2.176$

(.866)

$[-.169]$

Coptrol variables

(both oanels):

Husband's income,

other income, education,

Yes

Yes

Yes

Yes

Yes

Yes

and local unemployment

rate

Lagged own

employment

No

Yes

No

Yes

Yes

Yes

Other control

variables ${ }^{2}$

No

No

Yes

Yes

Yes

Yes

Age of sister

No

No

No

No

Yes

No

1. The data set is described in footnote 1 of Table 5. All income measures are in thousands of real dollars. In contrast to sister's employment, when the income measures in the sister's family were used, contemporaneous values mattered more than lagged values, and therefore are used in the table. The full set of control variables, is included in all specifications.

2. These are the control variables in columns (2), (4), and (6) of Table 1. 
Currently employed

Husband's income/ $\$ 1000$

Other income $/ \$ 1000$

Years of education

Local unemployment rate

Age

Number of children

Number of children aged one year or less

Black

Hispanic

Husband unemployed during year

Urban

Divorced, widowed, separated, or spouse absent

Number of individuals
.737

\section{All Sister/Sister Pairs} .656

14.064

(14.443)

.546

(2.904)

12.723

(2.142)

7.355

(3.313)

25.147

(3.058)

.991

(1.051)

.214

(.418)

.127

.171

.072

.156

346
Sister/Sister-in-Law Pairs Currenly Married Sister/Sister Pairs .678

12.761

16.902

(12.770)

(14.241)

.276

686

(.992)

(3.257)

12.682

12.789

(2.107)

7.617

7.225

(3.585)

24.954

25.389

(3.127)

1.082

1.050

(1.024)

(1.060)

\section{.236}

(.448)

.250

(.442)

.184

.170

.132

.059

.079

.751

.757

.161

305

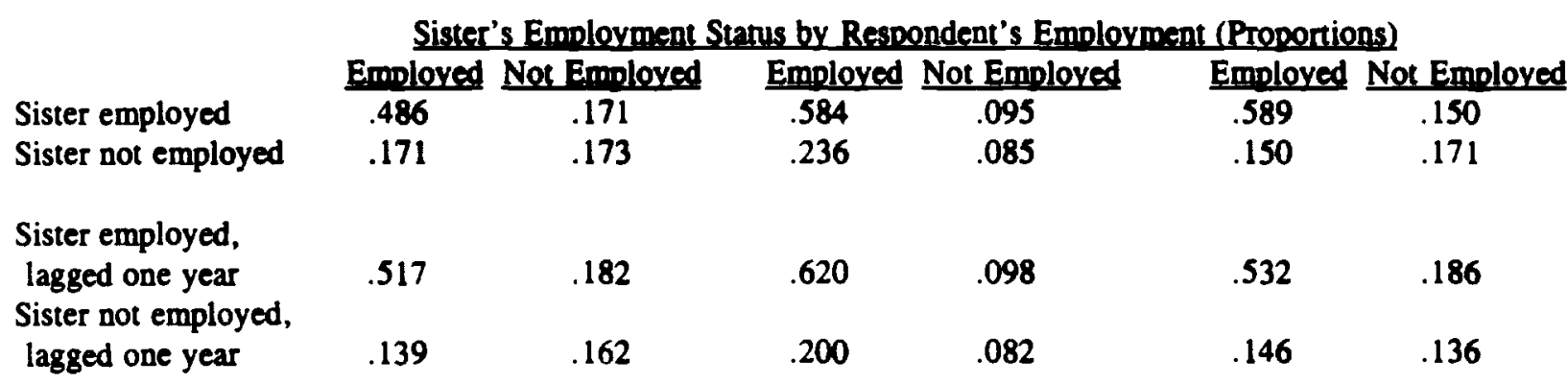

1. Standard deviations are reported in parentheses. See other tables details regarding the sample. Data from the second year on each woman are used. Husband's income and own income refer to labor income, and all income measures refer to the past calendar year. The income measures are top-coded. Because the top-codes vary across the years in the NLSY, sometimes rising and sometimes falling across the years, the smallest nominal top code for each income measure was chosen. The CPI was used to create a nominal top code for the other years of the survey, and the data were then treated as top-coded at those values. Finally, the income measures were deflated by the CPI. 